\title{
The fragmentation threshold of pyroclastic rocks
}

Printed in EARTH AND PLANETARY SCIENCE LETTERS 226 (1-2): 139-148 SEP 302004
Oliver Spieler $\stackrel{\text { a., \# }}{\text {, Ben Kennedy a, b, Ulrich Kueppers }}{ }^{\text {a }}$, Donald B. Dingwell a,
Bettina Scheu ${ }^{\text {a }}$, Jacopo Taddeucci a, c

a Earth and Environmental Sciences, LMU München, Theresienstrasse 41/III, 80333 Munich, Germany

b Earth and Planetary Sciences, McGill University, 3450 University Street, H3 A2 A7 Montreal, Canada

c INGV Roma, Via di Vigna Murata 605, 00143 Rome, Italy

\#～corresponding author: Tel.: +49-89-21804221, Fax.: +49-89-21804176, email: spieler@lmu.de

\begin{abstract}
In response to rapid decompression, porous magma may fragment explosively. This occurs when the melt can no longer withstand forces exerted upon it due to the overpressure in included bubbles. This occurs at a critical pressure difference between the bubbles and the surrounding magma. In this study we have investigated this pressure threshold necessary for the fragmentation of magma. Here we present the first comprehensive, high temperature experimental quantification of the fragmentation threshold of volcanic rocks varying widely in porosity, permeability, crystallinity, and chemical composition. We exposed samples to increasing pressure differentials in a high temperature shock tube apparatus until fragmentation was initiated. Experimentally, we define the fragmentation threshold as the minimum pressure differential that leads to complete fragmentation of the pressurized porous rock sample. Our results show that the fragmentation threshold is strongly dependent on porosity; high porosity samples fragment at lower pressure differentials than low porosity samples. The fragmentation threshold is inversely proportional to the porosity. Of the other factors, permeability likely affects the fragmentation threshold at high porosity values, whereas chemical composition, crystallinity and bubble size distribution appear to have minor effects. The relationship for fragmentation threshold presented here can be used to predict the minimum pressure differential necessary for the initiation or cessation of the explosive fragmentation of porous magma.
\end{abstract}

\section{Keywords}

Fragmentation, threshold, experimental, volcanology, magma, eruption, porosity, decompression 


\section{Introduction}

Among the processes that may trigger explosive eruptions, rapid decompression of pressurized, porous magma is highly unpredictable and potentially dangerous. Explosive eruptions are thought to initiate when (1) gas pressure overcomes the tensile strength of the rock or melt [1-4], (2) viscous strain rates are higher than the relaxational strain rate of the melt, [5, 6], or (3) magma interacts with external water [7-9]. Magma decompression can be triggered by sector collapse of a volcanic edifice (e.g. Mt. St. Helens, 1980 [10, 11]), plug removal or dome collapse (e.g. Soufrière Hills, Montserrat [12], Merapi [13]). The major cause of gas overpressure in magma is thought to be either second boiling by microlite growth [14-17] or disequilibrium degassing during rapid magma ascent [18]. The maximum gas pressure that spherical bubbles may withstand before failure depends on the bubble volume, the bubble wall thickness, and the tensile strength of the bubble walls [1-3]. Porosity controls both the volume of gas available for expansion and the thickness of the bubble walls. Starting from these simple considerations, a number of theoretical [1-3] and experimental [19-26] studies have considered the relationship between overpressure, porosity, and fragmentation of magma. Below, we present the first complete set of experiments at $850{ }^{\circ} \mathrm{C}$ defining the dependence of overpressure-driven fragmentation on porosity for a large variety of volcanic products. We use shock tube experiments to quantify the gas-overpressure required to overcome the tensile strength of magma $[19,20]$. The minimum pressure differential that leads to complete fragmentation of the pressurized sample in the shock tube is here defined as the fragmentation threshold $\left(\Delta \mathrm{P}_{\mathrm{fr}}\right)$.

We illustrate the discrepancy of the experimental data with previous theoretical parameterisations and discuss the parameters that influence the fragmentation behaviour. Finally, we discuss the implications of our results to volcanic eruptions.

\section{Methodology}

Fragmentation experiments were performed in the fragmentation bomb (Fig. 1), a shock tube apparatus [19-23, 25] consisting of three main units: (1) A cold seal Nimonic ${ }^{\mathrm{TM}}$ pressure vessel containing cylindrical samples at an experimental temperature of $850{ }^{\circ} \mathrm{C}$ and at pressures up to $35 \mathrm{MPa}$; (2) A system of three scored diaphragms that open at a reproducible, experimentally calibrated pressure differential, allowing precise pressurization of the sample; (3) A large steel tank at ambient pressure $(0.1 \mathrm{MPa})$ where the artificially generated pyroclasts collect after fragmentation. 
Samples are loaded in the pressure vessel that is externally heated at a rate of $\approx 15^{\circ} \mathrm{C} / \mathrm{min}$ to $850^{\circ} \mathrm{C}$. To prevent alteration of the sample due to water or oxygen, Argon 4.8 was used for sample pressurization. We find that $1 \mathrm{MPa}$ of Argon pressure during the heating procedure prevents thermally induced changes in the physical properties of the sample. Microscopic and SEM analysis of samples before heating, after heating, and after fragmentation does not show changes in overall porosity or bubble size distribution. Once at $850{ }^{\circ} \mathrm{C}$, the sample is pressurized to the desired experimental pressure. This procedure furthermore minimises the risk of diaphragm failure. After the diaphragms open, a rarefaction wave travels towards the sample at the sound velocity of the pressurized gas, giving a decompression rate $1-100 \mathrm{GPa} / \mathrm{s}$ depending on the initial pressure differential. If the pressure differential is sufficiently high, samples fragment brittlely layer-by-layer [21]. If the applied pressure differential is not high enough to entirely fragment the sample, the experiment is repeated at a higher pressure differential using a new cylinder drilled from the same sample, until complete fragmentation is achieved. The minimum pressure differential leading to complete fragmentation is defined as the fragmentation threshold. Prior to the experiments we performed thin section analysis and measured the percentage of interconnected and isolated pores (open and closed porosity) in the samples (by Helium pycnometry with a Accupyc 1330). The results presented here represent the conclusion of several years of experimental volcanology on volcanic materials with a wide range of porosity ( 2 to $85 \%$ ), crystallinity, and chemical composition that derive from a variety of eruption styles:

St. Helens grey dacite from the 1980 eruption; Merapi basaltic andesite from 1994 and 1998 pyroclastic flows; Santorini dacite from plinian fallout of the Minoan eruption; Unzen dacite from 1990-95 dome and vulcanian eruptions; Etna alkali basalt from ash explosions of the 2001 flank eruption; Campi Flegrei trachyte from the 4100 BP Agnano Monte Spina and the 1538 Monte Nuovo eruptions; and Montserrat andesite from the 1997 "Boxing day" vulcanian explosion (Fig. 2).

Experiments on the fragmentation behaviour of pyroclasts started with cylindrical samples (17 $\mathrm{mm}$ in diameter by $50 \mathrm{~mm}$ long) from St. Helens, Merapi and Unzen [22, 25]. For these first samples, the number of experiments performed is highest (Table 1). Usually, experiments were performed at small pressure steps $(0.2-0.5 \mathrm{MPa})$ to tightly constrain $\Delta \mathrm{P}_{\text {fr }}$. The resulting value was verified by repeated experiments. To reduce the potential influence of large phenocrysts (up to $20 \mathrm{~mm}$ in the case of Unzen), the set-up was changed to allow samples of up to $26 \mathrm{~mm}$ diameter and $60 \mathrm{~mm}$ length. Further experiments on Unzen 
samples were performed with this sample size. Based on results from experiments with samples of St. Helens, Merapi and Unzen, further experiments on samples from Etna, Santorini, Campi Flegrei and Montserrat were performed in order to check the potential influence of differing chemical compositions and textural features. The number of experiments on these samples is lower, as they were performed at pre-selected $\Delta \mathrm{P}$ values expected to be the threshold value for the given porosity. The results confirm this approach.

\section{The fragmentation threshold curve}

The experimental data (Table 1, approx. 400 experiments) show a strong correlation between porosity and $\Delta \mathrm{P}_{\text {fr }}$ (Fig. 2). The value of the fragmentation threshold given in Table 1 has to be interpreted as a pressure range of $\pm 0.5 \mathrm{MPa}$. The curve described by the data can be closely fitted by an inversely proportional relationship between porosity and fragmentation threshold.

\subsection{Modelling experimental results}

Literature contains several proposals that a fragmentation criterion can be described in terms of a range of porosity, e.g., 75-83,5 vol.\% [27], 68-79 vol.\% [28-30] and 64 vol.\% [31]. Our results indicate that a magma fragmentation criterion cannot be solely based on values/ranges of porosity without considering pressure (Fig. 2). It is clear from our work that magma may fragment at porosity values far below earlier fragmentation criterions depending on the amount of decompression. Additionally, the variety of porosity found in pyroclasts from natural explosive eruptions confirms this observation. In order to obtain more realistic insights into the dynamics and propagation of fragmentation and its consequences for explosive eruptions, a more sophisticated parameterisation of magma fragmentation is necessary. For this, a brittle failure criterion based on pressurized vesicles [1-3] is more appropriate and more consistent with our experimental data.

In the equations provided by all of these models, the importance of porosity and the tensile strength of glass $(\sigma)$ on the overpressure at bubble wall failure is clearly stated. These equations can therefore be rearranged and solved to relate porosity $(\Phi)$ with overpressure $(\Delta \mathrm{P})$ at failure, and then model our experimental data set. In particular, we tried to model the $\Phi$ vs $\Delta \mathrm{P}_{\text {fr }}$ curve of Fig. 2 using the models of McBirney and Murase [1], Alidibirov [2], and Zhang [3].

McBirney and Murase [1] use the Griffith [32] equation for critical tensile stress to modify the bulk properties of the melt. They then used MacKenzie's [33] equation for the strength 
of elastic porous material to define Young's modulus for bubbly magma with up to $50 \%$ porosity $\left(\mathrm{E}_{\mathrm{b}}\right)$. This gave his equation (6).

$$
\begin{array}{lr}
\sigma=\left(4 \mathrm{E}^{*} \mathrm{~s} / \pi^{*} \mathrm{c}\right)^{1 / 2} & \text { (McBirney's eq. 4) } \\
\mathrm{E}_{\mathrm{b}}=\mathrm{E}^{*}(1-1.7 * \Phi) & \text { (McBirney's eq. 5) } \\
\Delta \mathrm{P}=\left(2 * \mathrm{n}^{2 / 3} \mathrm{~s} / \Phi\right) *(4 * \mathrm{n} * \pi / 3 \Phi)^{1 / 3}+1 / \Phi\left(4 \mathrm{E}(1-1.7 * \Phi) \mathrm{s} / \pi^{*} \mathrm{c}\right)^{1 / 2} & (\text { McBirney's eq. 6) }
\end{array}
$$

where $\mathrm{n}=$ number of bubbles, $\mathrm{s}=$ surface tension, $\mathrm{E}=$ Young's modulus for magma, $\mathrm{c}=$ circumference, $\sigma=$ tensile strength of glass, $\Phi=$ open porosity.

Due to the assumptions above, McBirney and Murase's equation 6 is most useful for porosity below 50\%, which concerns the second term in equation 6 [1]. Eq. 4 can then be substituted into eq. 6 to give the porosity-threshold relation:

$$
\Delta \mathrm{P}=\sigma / \Phi *(1-1.7 * \Phi)^{1 / 2}
$$

that we used to model our data.

More recent models use a different approach, considering the stress distribution around pressurized, spherical bubbles.

Alidibirov [2] considers the tangential stress distribution of a thin-walled sphere, considering each bubble individually, radius, with a bubble wall thickness equal to half the distance to the neighbouring bubble. As the pressure in the bubble is increased, stress builds up; higher stress can break thicker bubble walls. His equations (2) and (3)

$$
\begin{aligned}
& \mathrm{a} / 1=\Phi^{1 / 3 /}\left(1-\Phi^{1 / 3}\right) \\
& \sigma=\Delta \mathrm{P} / 2 * \mathrm{a} / 1
\end{aligned}
$$

can be combined as:

$$
\Delta \mathrm{P}=\sigma^{*} 2 /\left(\left(\Phi^{1 / 3}\right)^{*}(1-\Phi)^{1 / 3}\right)
$$

where $\mathrm{a}=$ radius, $\mathrm{l}=$ bubble wall thickness.

Zhang [3] uses an approach similar to Alidibirov but he considers a tangential stress distribution throughout the bubble wall where the maximum stress occurs at the inner bubble wall:

$$
1+2 \Phi / 2(1-\Phi) \Delta \mathrm{P}>\sigma
$$

Zhang's eq. 4 can be rearranged to:

$$
\Delta \mathrm{P}>\sigma /(1+2 * \Phi) /(2-2 * \Phi)
$$

Following McBirney and Murase [1], fragmentation of a porous media occurs when the total force exerted by the entrapped gas exceeds the tensile strength of the liquid matrix over the same cross sectional area. Accordingly, we modelled our experimental data using a simple relationship, that considers an effective tensile strength $\left(\sigma_{m}\right)$ of a compound matrix against bubble overpressure. 


$$
\Delta \mathrm{P}_{\mathrm{fr}}=\sigma_{\mathrm{m}} / \Phi
$$

With $\Delta \mathrm{P}_{\text {fr }}$ being the fragmentation threshold.

All models approximate the general shape of the experimental data set, each one with specific deviations. Possible causes for the deviations are discussed in the next section.

\subsection{Comparison of experimental results with fragmentation theory}

Comparing equations 1-3 with our experimental results helps to understand the control parameters for brittle fragmentation upon rapid decompression. Tensile strength is a critical parameter in resisting the tangential stress. Our experimentally determined $\Delta \mathrm{P}_{\mathrm{fr}}$ is the pressure differential at failure for different porosities, and since the tensile strength equals the maximum tangential stress at the bubble walls, our data can be substituted into the theoretical models to use the stress to give an estimate of the tensile strength of the samples.

All models require different values of tensile strength to achieve the best fit to the data (Fig. 3, Table 2). McBirney and Murase achieves the best fit using a tensile strength of 1.5 MPa. The models of pressurized spheres of Zhang and Alidibirov achieve their best fit with tensile strength values of 9.4 and 5.9 MPa, respectively (Fig. 3). However eq. 2 and our eq. 4 give considerably better fits than the other models. Experiments on a variety of glasses have shown that values of tensile strength of glass may vary from several 10 s to several 100s $\mathrm{MPa}$ [34, 35], almost independently of chemical composition [36]. The discrepancies between the models and the suitable tensile strength values arise from three main factors:

1) Alidibirov [2] and Zhang [3] use models based on the stress distribution around single spherical bubbles. Zhang's model is the more theoretically accurate of the two models as he considers the stress distribution throughout the bubble wall. However, Zhang's model underestimates the fragmentation threshold at low porosities and gives a finite value of the threshold even in the zero porosity case. We speculate that our data deviate from Zhang's model because this model predicts the differential pressure required for vesicle-scale crack initiation, whereas our experimental results are the pressure differential required for the total failure of the sample. The deviation of our results from values achieved with Zhang's model is highest at low porosities; low porosities reflect thick bubble walls and therefore require pressure not only to initiate cracks but also to propagate cracks in order to cause complete failure of the sample. The fit at high porosities is better, probably because the pressure required for crack initiation is similar to the pressure required for the total failure of the sample. 
2) We would like to point out that the theoretical models (eq. 1-3) deal with the tensile strength of a glassy matrix whereas our model deals with the tensile strength of a compound matrix. Additionally, theoretical models assume spherical bubbles with uniform stress distribution. Non spherical bubbles or bubble walls with protruding crystals or microlites (Fig. 4) will focus the stress, give a locally higher tangential stress [37], and result in a weakening of the matrix. Our experimental results are achieved from experiments on natural samples. These samples rarely have spherical bubbles and, as a consequence, the tangential stress at the bubble wall is likely to be locally much higher than estimated assuming spherical bubbles. Dehydrated glass may show micro-fractures around vesicles, which dramatically reduce the effective tensile strength [34].

3) Theoretical models assume mono-disperse, homogeneously distributed bubbles in a glass matrix. However, complex vesicle and crystal textures in natural samples may have large effects. For example, bubbles with restricted bubble size distributions can have relatively thin bubble walls for a corresponding porosity and failure will occur at lower pressure differentials. Crystals are elastic and have a tensile strength different from glass. Therefore, crystallinity affects the bulk tensile strength of the rock. Earlier studies show that high microlite content may increase the tensile strength of the sample [23] and thus may significantly influence $\Delta \mathrm{P}_{\mathrm{fr}}$. However, if a high percentage of crystals are already cracked when fragmentation occurs, this will reduce the overall tensile strength of the sample and accordingly the resultant $\Delta \mathrm{P}_{\mathrm{fr}}$.

The models also assume closed porosity, whereas our samples are characterized by mainly interconnected pores. These pores allow gas flow through the samples and the accumulation and release of gas pressure, e.g., degassing of active conduits and domes [38-41]. Comparing the experimentally determined speed of the fragmentation front $\left(2-300 \mathrm{~ms}^{-1}\right)$ and the speed of the gas expansion $\left(>300 \mathrm{~ms}^{-1}\right)[25,26]$, it becomes apparent that permeable gas flow can significantly reduce the pressure differential in and below the fragmenting layer [38]. Generally, gas flow within the sample is too slow to effectively reduce the pressure during the experiments. However, the anomalously high permeability of the Campi Flegrei samples [38] and their anomalously high $\Delta \mathrm{P}_{\mathrm{fr}}$ indicate that gas escape prior to fragmentation may have a major influence on the fragmentation behaviour.

An additional consideration is that the melt phase in the samples behaves like a fluid because the samples were heated above the glass transition temperature $\left(T_{g}\right)$ during the experimental procedure. Surface tension and bubble expansion would become important if the samples were behaving like a liquid at the time of decompression and fragmentation 
$[1,42,43]$. However, thin section and SEM images of our samples show no evidence of bubble deformation during the experiments. We conclude that, due to the relatively high decompression and cooling rates, viscous relaxation and expansion did not occur in any of our samples. This explains why the chemical composition and the associated viscosity differences between samples did not significantly affect the fragmentation threshold.

In order to fully understand the relationship between the fragmentation threshold of volcanic rocks and their porosity, general textural trends between dome rocks, scoria and pumice need to be quantified. However, the relative insensitivity of the threshold curve to the above factors (with the possible exception of permeability) relegates them to a second order effect in respect with the first order control exerted by porosity.

\section{Implications for explosive volcanism}

Our results may have important implications for the mechanism of initiation and cessation of volcanic eruptions. Our threshold curve allows us to predict how much overpressure is required to start explosive fragmentation of magma of known porosity.

Current techniques for the geophysical and geochemical monitoring of active volcanoes provide estimates of the pressurization state of magma at depth [44]. This information serves as an input parameter for numerical models that calculate the porosity and pressure of the magma [45]. In a scenario of expected dome collapse, sector collapse, or vulcanian blasts, once pressure and porosity of the magma in the conduit can be calculated, the threshold curve may be used to estimate the amount of decompression required to trigger magma fragmentation and start an eruption.

The cessation of explosive activity is at present poorly understood. Our results indicate that static magma will cease to erupt if the pressure differential falls below the fragmentation threshold, i.e. the fragmentation front reaches low porosity magma or the pressure differential is reduced during eruption.

The threshold curve provides a new constraint on the overpressure involved in the explosive fragmentation of past eruptions. Using our eq. 4, pyroclasts collected from eruptions can be used to estimate overpressures during eruptions [46]. This approach, in combination with field density measurement of large pyroclasts [47], may help to better understand the local fragmentation dynamics of heterogeneous domes and conduit fillings.

\section{Conclusion}

These first comprehensive determinations of the high-T fragmentation threshold for a wide range of natural magma samples confirms that the fragmentation threshold is dominantly 
dependent on porosity and that magma composition has little effect. Brittle deformation dominates over viscous deformation during our experiments due to the high decompression rates, this is probably also the case during Vulcanian eruptions. In addition, we show how the fragmentation threshold of volcanic rocks during static decompression deviates from previous mathematical models. We indicate that assumptions made in previous fragmentation models concerning i) the criterion for fragmentation (crack initiation vs. larger-scale failure), ii) shape of the vesicles and iii) the relationship between porosity and bubble wall thickness, crystallinity and permeability may be the reasons for the misfit of the data. These textural considerations will undoubtedly require further experimental investigation.

Due to its robust experimental basis, the porosity-fragmentation threshold relationship in eq. 4 is applicable to magma with a wide range of chemical and textural composition, and, beside potential application to the study of past eruptions, it may be directly incorporated into models of explosive eruption hazard.

\section{Acknowledgements}

The visit of Ben Kennedy to Munich was funded by the IQN Georisk network (hosted at University of Munich) and the EU Research training network (Volcano Dynamics). Financial support was provided from the German Science Foundation (DFG, project DI 431/20-1). Jacopo Taddeucci was supported by a Marie Curie Fellowship of the European Community programme under contract number HPMF-CT-2002-01670. The paper benefited from discussions with Mie Ichihara and Hugh Tuffen and the precise comments of the three reviewers T. Koyaguchi, L. Mastin and anonymous. 


\section{References}

[1] A.R. McBirney, T. Murase, Factors governing the formation of pyroclastic rocks, Bull. Volcanol. 34 (1970) 372-384.

[2] M. Alidibirov, A model for viscous magma fragmentation during volcanic blasts, Bull. Volcanol. 56 (1994) 459-465.

[3] Y. Zhang, A criterion for the fragmentation of bubbly magma based on brittle failure theory, Nature 402 (1999) $648-650$.

[4] B. Zimanowski, R. Büttner, V. Lorenz, H.-G. Häfele, Fragmentation of basaltic melt in the course of explosive volcanism, J. Geophys. Res. 102 (1997) 803-814.

[5] P. Papale, Strain-induced magma fragmentation in explosive eruptions, Nature 397 (1999) 425-428.

[6] D.B. Dingwell, S.L. Webb, Structural relaxation in silicate melts and non-Newtonian melt rheology in igneous processes. Physics and Chemistry of Minerals 16 (1989) 508-516.

[7] K.H. Wohletz, Mechanisms of hydrovolcanic pyroclast formation: grain-size, scanning electron microscopy, and experimental studies, J. Volcanol. Geotherm. Res. 17 (1983) 31-63.

[8] B. Zimanowski, G. Fröhlich, V. Lorenz, Quantitative experiments on phreatomagmatic explosions, J. Volcanol. Geotherm. Res. 48 (1991) 341-358.

[9] B. Zimanowski, G. Fröhlich, V. Lorenz, Experiments on steam explosions by interaction of water with silicate melts, Nucl. Engrg. Des. 155 (1995) 335-343.

[10] R.P. Hoblitt, D.C. Miller, J.W. Vallance, Origin and stratigraphy of the deposits produced by the May 18 directed blast. In: P.W. Lipman \& D.R. Mullineaux (eds.) The 1980 eruptions of Mount St. Helens, Washington, 1981, 401-419.

[11] B. Voight, R.J. Janda, H. Glicken, P.M. Douglass, Nature and mechanics of the Mount St. Helens rockslide-avalanche of 18 May 1980. Geotechnique 33 (1983) 243-273.

[12] T.H. Druitt, S.R. Young, B. Baptie, C. Bonadonna, E.S. Calder, A.B. Clarke, P.D. Cole, C.L. Harford, R.A. Herd, R. Luckett, G. Ryan, B. Voight. Episodes of cyclic Vulcanian explosive activity with fountain collapse at Soufrière Hills Volcano, Montserrat. In: Druitt TH and Kokelaar BP (eds.) The Eruption of Soufrière Hills Volcano, Montserrat, from 1995 to 1999. Geological Society, London, Memoirs, 21 (2002) 281-306.

[13] J.M. Bardintzeff, Merapi Volcano (Java, Indonesia) and Merapi-Type Nuée Ardente. Bull. Volcanol. 47 (1984) 433-446.

[14] S. Tait, C. Jaupart, S. Vergniolle, Pressure, gas content and eruption periodicity of a shallow, crystallising magma chamber, Earth Planet. Sci. Lett. 92 (1999) 107-123.

[15] R.S.J. Sparks, S.R. Young, J. Barclay, E.S. Calder, P. Cole, B. Darroux, M.A. Davies, T.H. Druitt, C. Harford, R. Herd, M. James, A.-M. Lejeune, G. Norton, G. Skerrit, M.V. Stasiuk, N.F. Stevens, J. Toothill, G. Wadge , R. Watts, Magma production and growth of the lava dome of the Soufrière Hills 
Volcano, Montserrat, West Indies: November 1995 to December 1997, Geophys. Res. Lett. 25 (1998) 3421-3424.

[16] J. Stix, R.C. Torres, L.M. Narvaez, G.P.J. Cortés, J.A. Raigosa, D.M. Gómez, R. Castonguay, A model of vulcanian eruptions at Galeras volcano, Colombia. J. Volcanol. Geotherm. Res. 77 (1997) 285-303.

[17] O. Navon, V. Lyankhovsky, Vesiculation processes in silicic magmas, in: J.S. Gilbert, R.S.J. Sparks, (eds.) The physics of explosive volcanic eruptions, Geol. Soc. London, Spec. Pub. 145 (1998) 27-50.

[18] H. Massol, C. Jaupart, The generation of gas overpressure in volcanic eruptions, Earth Planet. Sci. Lett. $166(1999) 57-70$.

[19] M. Alidibirov, D.B. Dingwell, Magma fragmentation by rapid decompression, Nature 380 (1996) 146148.

[20] M. Alidibirov, D.B. Dingwell, An experimental facility for investigation of magma fragmentation by rapid decompression, Bull. Volcanol. 58 (1996) 411-416.

[21] M. Alidibirov, D.B. Dingwell, Three fragmentation mechanisms for highly viscous magma under rapid decompression, J. Volcanol. Geotherm. Res. 100 (2000) 413-421.

[22] O. Spieler, M. Alidibirov, D.B. Dingwell, Grain-size characteristics of experimental pyroclasts of 1980 Mount St. Helens cryptodome dacite: Effects of pressure drop and temperature, Bull. Volcanol. 65 (2003) 90-104.

[23] C. Martel, D.B. Dingwell, O. Spieler, M. Pichavant, M. Wilke, Experimental fragmentation of crystal- and vesicle-bearing silicic melts, Bull. Volcanol. 63 (2001) 345-359.

[24] D.B. Dingwell, Magma degassing and fragmentation: Recent experimental advances, in: A. Freundt, M. Rosi (Ed.) From Magma to Tephra. Modelling physical processes of explosive volcanic eruptions. Elsevier, Amsterdam (1998) 1-23.

[25] O. Spieler, D.B. Dingwell, M. Alidibirov, Magma fragmentation speed: An experimental determination, J. Volcanol. Geotherm. Res. 129 (2004) 109-123.

[26] B. Scheu, O. Spieler, D.B. Dingwell, Dynamics of Explosive Volcanism at Unzen: an experimental Contribution, Bull. Volcanol. submitted

[27] R.S.J. Sparks, The dynamics of bubble formation and growth in magmas: a review and analysis, J. Volcanol. Geotherm. Res. 28 (1978) 257-274.

[28] R.S.J. Sparks, J. Barclay, C. Jaupart, H.M. Mader, J.C. Phillips, Physical aspects of magma degassing. I. Experimental and theoretical constraints on vesiculation, Rev. Mineral. 30 (1994) 414-445.

[29] N. Thomas, C. Jaupart, S. Vergniolle, On the vesicularity of pumice, J. Volcanol. Geotherm. Res. 99 (1994) 15633-15644.

[30] J. Barclay, M.R. Carroll, B.F. Houghton, C.J.N. Wilson, Pre-eruptive volatile content and degassing history of an evolving peralkaline volcano, J. Volcanol. Geotherm. Res. 74 (1996) 75-87.

[31] J.E. Gardner, R.M.E. Thomas, C. Jaupart, S. Tait, Fragmentation of magma during plinian volcanic eruptions, Bull. Volcanol. 58 (1996) 144-162. 
[32] A.A. Griffith, The phenomena of rupture and flow in solids. Trans.Phys. Soc. London, Ser.A, 22 (1921) 163-198

[33] J.K. MacKenzie, The elastic constants of a solid containing spherical holes, Proc. Phys. Soc. London, B, 63 (1950) 1-11.

[34] C. Romano, J. Mungall, T. Sharp, D.B. Dingwell, Tensile strengths of hydrous vesicular glasses: an experimental study, American Mineralogist 81 (1996) 1148-1154.

[35] H. Scholze, Glas - Natur, Struktur und Eigenschaften, Springer-Verlag 1988

[36] S.L. Webb, D.B. Dingwell, NonNewtonian rheology of igneous melts at high stresses and strain rates: Experimental results for rhyolite, andesite, basalt and nephelinite, J. Geophys. Res. 95 (1990) 1569515701.

[37] J.E. Mungall, N.S. Bagdassarov, C. Romano, D.B. Dingwell, Numerical modelling of stress generation and microfracturing of vesicle walls in glassy rocks, J. Volcanol. Geotherm. Res. 73 (1996) 33-46.

[38] S. Mueller, O. Spieler, B. Scheu, D.B. Dingwell, Permeability and degassing of dome lavas undergoing rapid decompression: an experimental determination. (submitted to Bull. Volcanol., 2003)

[39] C. Jaupart, Gas loss through conduit walls during eruption, in: J.S. Gilbert, R.S.J. Sparks (Ed.) Physics of Explosive Volcanic Eruptions, Geol. Soc. London Spec. Pub. 145 (1998), 73-90.

[40] J.C. Eichelberger, C.R. Carrigan, H.R. Westrich, R.H. Price, Non-explosive silicic volcanism, Nature 323 (1986) 598-602.

[41] C. Klug, K.V. Cashman, Vesiculation of May 18, 1980, Mt. St. Helens magma, Geology 22 (1994) 468472.

[42] M. Ichihara, D. Rittel, B. Sturtevant, Fragmentation of a porous viscoelastic material: Implications to magma fragmentation, J. Geophys. Res. 106 (2002) 2226-2239.

[43] D.B. Dingwell, Volcanic Dilemma: Flow or blow? Science 273 (1996) 1054-1055.

[44] J. Neuberg, C. O'Gorman, A model of the seismic wavefield in gas-charged magma: application to the Soufrière Hills Volcano, Montserrat, in: T. H. Druitt, B. P. Kolelaar (Ed.) The Eruption of the Soufrière Hills Volcano, Montserrat, from 1995 to 1999. Geol. Soc. London Memoirs (2002), 603-609.

[45] S. Sturton, J. Neuberg, The effects of a decompression on seismic parameter profiles in a gas-charged magma, J. Volcanol. Geotherm. Res. 128 (2003) 187-199.

[46] J. Taddeucci, O. Spieler, B. Kennedy, M. Pompilio, D.B. Dingwell, P. Scarlato, Experimental and analytical modeling of basaltic ash explosions at Mt. Etna, Italy, 2001. J. Geophys. Res., in press.

[47] U. Kueppers, B. Scheu, O. Spieler, D.B. Dingwell, Field-based density measurements as tool to identify pre-eruption dome structure: set-up and first results from Unzen volcano Japan, J. Volcanol. Geotherm. Res. 2004 accepted for publication.

[48] S. Nakada, Y. Motomura, Petrology of 1990-1995 eruption, 1999. J. Volcanol. Geotherm. Res. 89, 173196. 
[49] J.E. Hammer, K.V. Cashman, B. Voight, Magmatic processes revealed by textural and compositional trends of Merapi dome lavas, 2000. J. Volcanol. Geotherm. Res. 100, 165-192.

[50] J. Taddeucci, M. Pompilio, P. Scarlato, Monitoring the explosive activity of the July-August 2001 eruption of Mt. Etna (Italy) by ash characterization, 2002. Geophys Res Lett 29:71

[51] M.A. Di Vito, R. Isaia, G. Orsi, J. Southon, S. de Vita, M. D’Antonio, L. Pappalardo, M. Piochi, Volcanism and deformation since 12,000 years at the Campi Flegrei caldera (Italy), 1999, J. Volcanol. Geotherm. Res. 91, 221-246.

[52] S. de Vita, G. Orsi, L. Civetta, A. Carandente, M. D’Antonio, A. Deino, T. di Cesare, M.A. Di Vito, R.V. Fisher, R. Isaia, E. Marotta, A. Necco, M. Ort, L. Pappalardo, M. Piochi, J. Southon, The Agnano-Monte Spina eruption (4100 years BP) in the restless Campi Flegrei caldera (Italy), 1999, J. Volcanol. Geotherm. Res. 91, 269-301.

[53] T.H. Druit, R.A. Mellors, D.M. Pyle, et al., Explosive volcanism on Santorini, Greece, 1989, Geol. Mag. $126,95-126$

[54] G.F. Zellmer, C.J. Hawkesworth, R.S.J. Sparks, L.E. Thomas, C.L. Harford, T.S. Brewer, S.C. Loughlin, Geochemical evolution of the Soufrière Hills volcano, Montserrat, Lesser Antilles volcanic arc, 2003, J. Petrol. 44, 1349-1374

[55] M. Alidibirov, D.B. Dingwell, R.J. Stevenson, K.U. Hess, S.L. Webb, J. Zinke, Physical properties of the 1980 Mount St. Helens cryptodome magma, 1997, Bull. Volcanol. 59, 103-111 


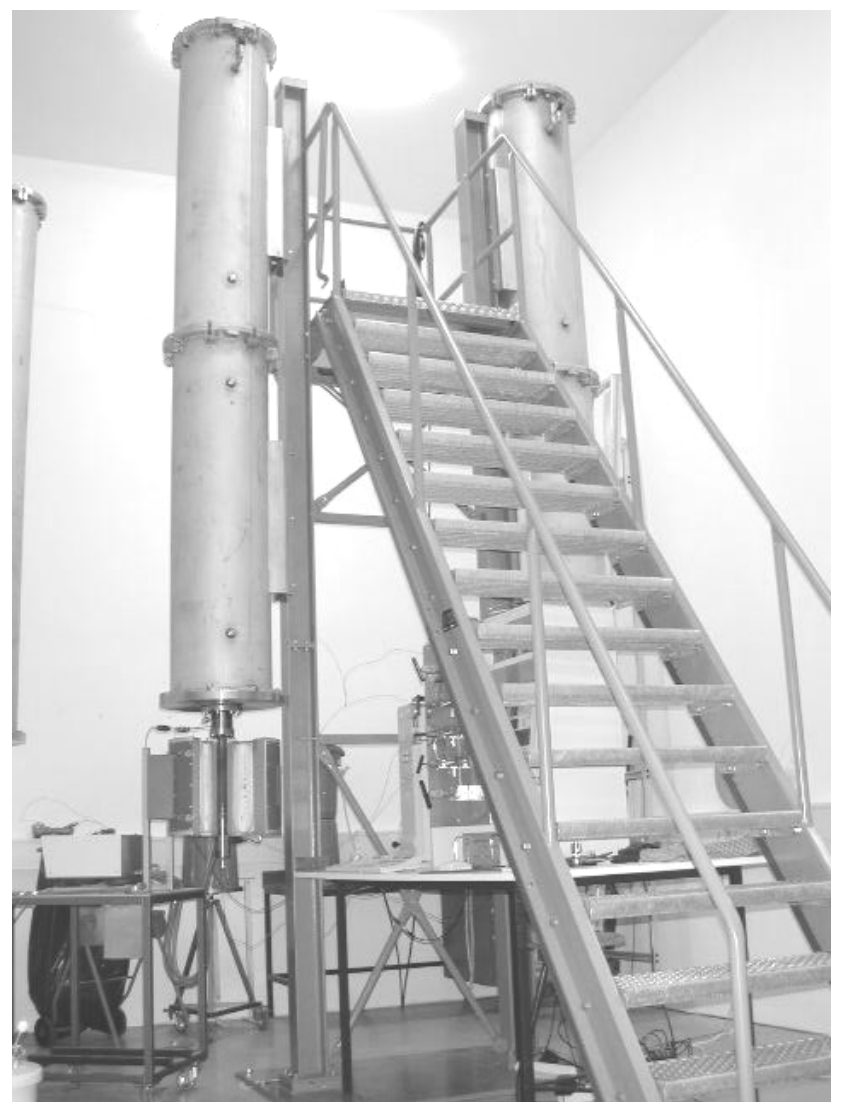

Fig.1: Image of the fragmentation bomb, for details see [25]. 


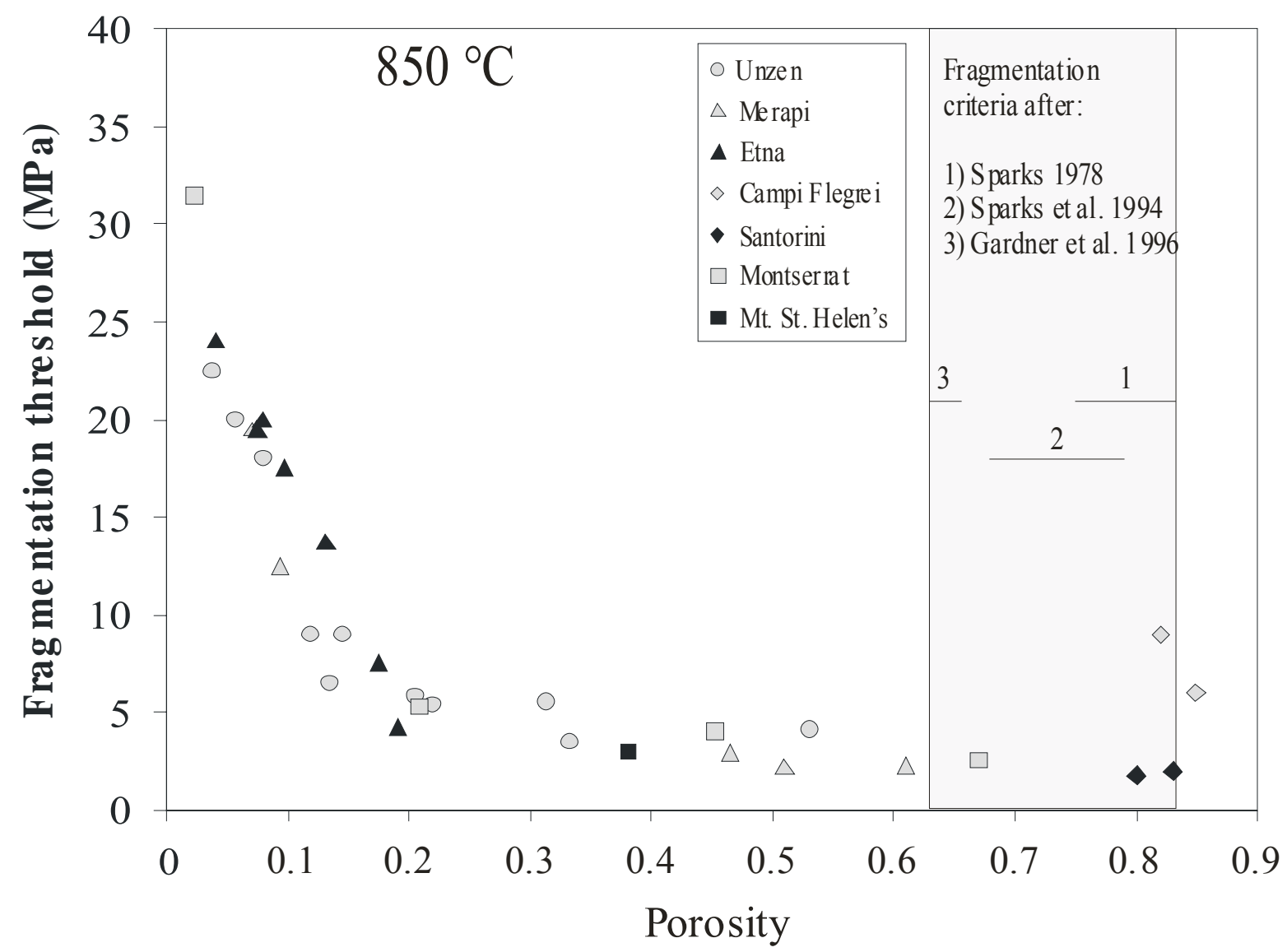

Fig. 2: The samples used in the present study were collected at seven different volcanoes or volcanic centres and represent a broad range of composition and porosity ( $2-85$ vol.\%). The experimental data (representing approx. 400 experiments, see Table 1) show a strong relation between porosity and the fragmentation threshold at $850{ }^{\circ} \mathrm{C}$. (Note that porosity/100 is plotted at the $\mathrm{x}$-axis.)

The grey box shows the range of different earlier fragmentation criteria defined by bubble coalescence [27,28] and shear induced foam instability [31]. (Note: The early fragmentation criteria depend only on porosity and do not correspond to any pressure value. The position of the lines does not correspond to any y-value.) 


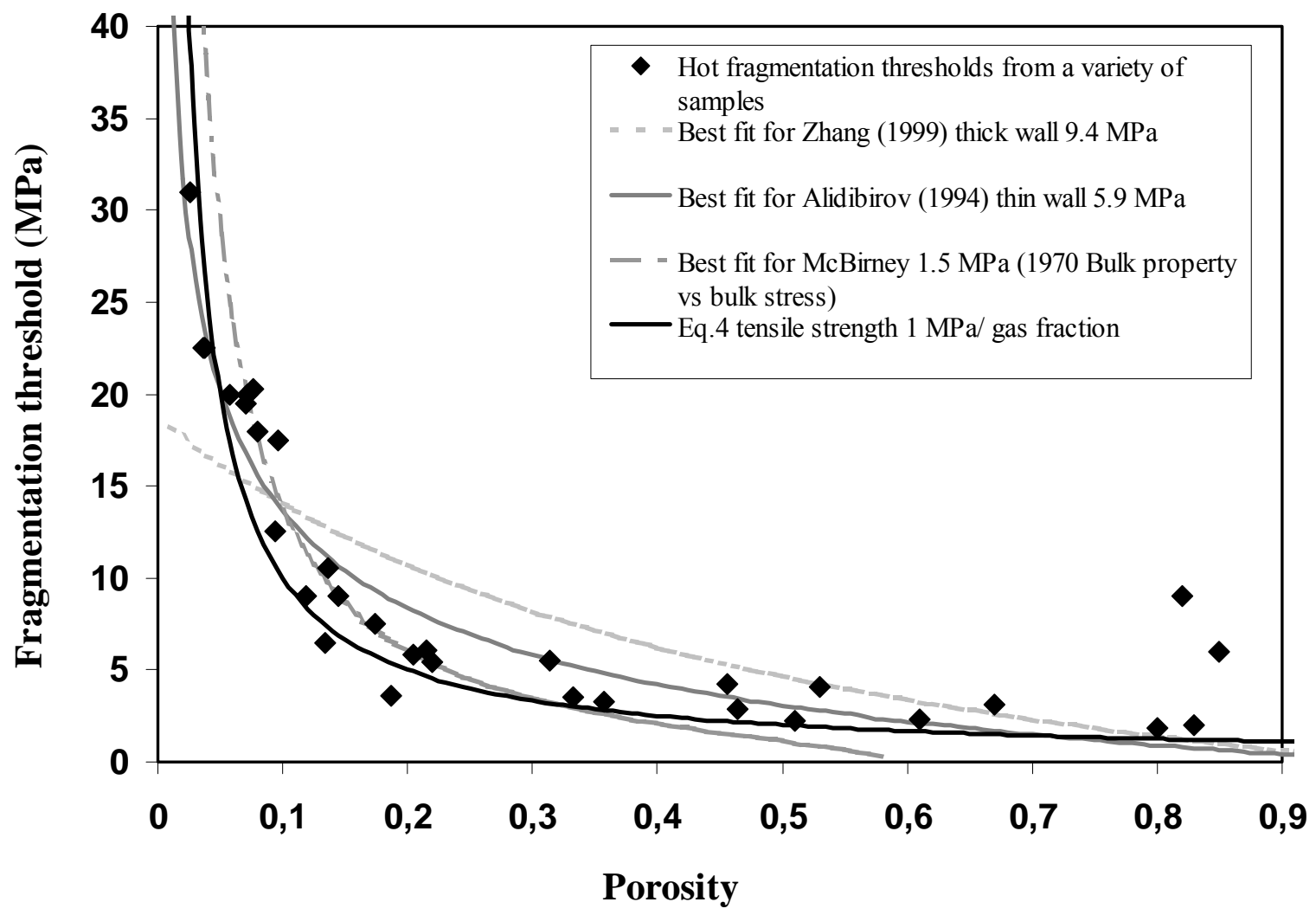

Fig. 3: Plot of 1/porosity vs. the evaluated fragmentation threshold values at $850{ }^{\circ} \mathrm{C}$ and comparison of our eq. 4 with the best fit of the theoretical models [1, 2, 3]. It is apparent that the best fit of these models is achieved using different values of tensile strength. 


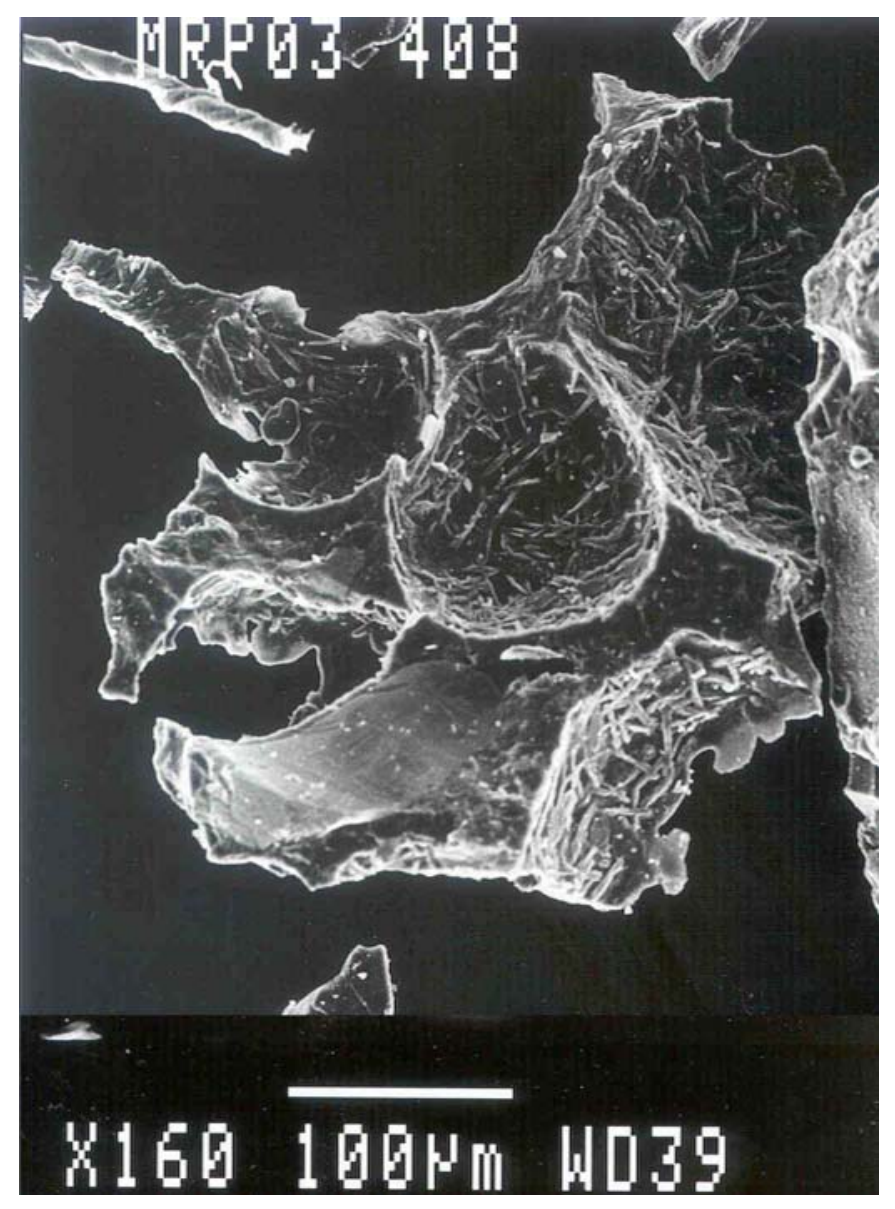

Fig. 4: SEM picture of Merapi basaltic andesite showing microlites deforming the bubble walls and thereby strongly influencing the stress distribution. 


\begin{tabular}{|c|c|c|c|c|c|c|}
\hline $\begin{array}{l}\text { Sample } \\
\text { origin }\end{array}$ & $\begin{array}{l}\text { Diameter } \\
(\mathrm{mm})\end{array}$ & \begin{tabular}{|l|}
$\mathrm{T}_{\text {experiment }}$ \\
$\left({ }^{\circ} \mathrm{C}\right)$
\end{tabular} & $\begin{array}{l}\text { Porosity }(\%) \\
\text { Open/total }\end{array}$ & $\begin{array}{l}\text { Threshold } \\
(\mathrm{MPa})\end{array}$ & \begin{tabular}{|l|} 
Numbers of \\
Experiments
\end{tabular} & $\begin{array}{l}\text { Covered pressur } \\
\text { range }(\mathrm{MPa})\end{array}$ \\
\hline Unzen (00 A) & 26 & 850 & $3.80 / 4.40$ & 22.5 & 7 & $20-30$ \\
\hline Unzen (01 B) & 25 & 850 & $5.70 / 6.00$ & 20 & 3 & $20-25$ \\
\hline Unzen (ENSP) & 17 & 850 & $8.00 / 8.60$ & 18 & 31 & $4.8-18$ \\
\hline Unzen $(00 \mathrm{~B})$ & 26 & 850 & $11.90 / 14.50$ & 9 & 5 & $7.5-20$ \\
\hline Unzen (00 E) & 26 & 850 & $14.10 / 16.60$ & 6.5 & 6 & $5-20$ \\
\hline Unzen & 17 & 850 & $14.50 / 16.80$ & 9 & 28 & $1.2-9$ \\
\hline Unzen (01 C) & 25 & 850 & $20.45 / 21.30$ & 5.8 & 10 & $3-15$ \\
\hline Unzen & 17 & 850 & $22.00 / 22.90$ & 5.4 & 34 & $2-5.3$ \\
\hline Unzen $(00 \mathrm{G})$ & 26 & 850 & $34.30 / 35.60$ & 5.5 & 6 & $4-20$ \\
\hline Unzen $(00 \mathrm{~F})$ & 26 & 850 & $33.60 / 36.00$ & 3.5 & 5 & $3-20$ \\
\hline Unzen (BKB) & 25 & 850 & $53.90 / 59.90$ & 4.1 & 3 & $3-10$ \\
\hline Merapi (9618) & 17 & 850 & $7.00 / 7.40$ & 19.5 & 26 & $10-19.5$ \\
\hline Merapi (9615) & 17 & 850 & $9.40 / 10.10$ & 12.5 & 36 & $2-13$ \\
\hline Merapi (9608) & 17 & 850 & $46.40 / 46.80$ & 2.9 & 26 & $0.6-2.9$ \\
\hline Merapi (9612) & 17 & 850 & $51.00 / 51.30$ & 2.2 & 19 & $0.8-2.5$ \\
\hline Merapi (9603) & 17 & 850 & $61.00 / 61.30$ & 2.3 & 37 & $0.5-2.5$ \\
\hline Etna (\# 6) & 17 & 850 & $3.60 / 4.10$ & 23 & 2 & $20-23$ \\
\hline Etna (\# 7) & 17 & 800 & $6.20 / 7.40$ & 20 & 1 & 19.5 \\
\hline Etna (\# 5) & 17 & 900 & $7.60 / 7.80$ & 20.5 & 2 & $8-20$ \\
\hline Etna (\# 2) & 17 & 850 & $9.70 / 9.75$ & 18 & 6 & $7.5-17.5$ \\
\hline Etna (\# 4) & 17 & 830 & $13.60 / 13.70$ & 14.5 & 2 & $10-14$ \\
\hline Etna (\# 1) & 17 & 850 & $17.40 / 17.50$ & 8 & 2 & $4.7-7.5$ \\
\hline Etna (\# 8) & 17 & 850 & $18.70 / 19.30$ & 4 & 1 & 3.6 \\
\hline Campi Flegrei & 26 & 850 & $82.00 / 82.50$ & 9 & 5 & $0.5-10$ \\
\hline Campi Flegrei & 26 & 850 & $85.00 / 85.50$ & 6 & 5 & $0.5-10$ \\
\hline Santorini & 26 & 850 & $80.00 / 80.50$ & 1.8 & 18 & $0.5-1.9$ \\
\hline Santorini & 26 & 850 & $83.00 / 83.50$ & 2 & 16 & $0.6-2$ \\
\hline Montserrat & 26 & 850 & $3.10 / 4.10$ & 31 & 2 & $30-35$ \\
\hline Montserrat & 26 & 850 & $20.10 / 21.00$ & 6 & 1 & 6 \\
\hline Montserrat & 26 & 850 & $44.40 / 49.20$ & 5 & 4 & $4.3-15$ \\
\hline Montserrat & 26 & 850 & $68.80 / 73.40$ & 3.2 & 5 & $2-15$ \\
\hline St. Helens & 17 & 850 & $36.00 / 41.00$ & 2.7 & 42 & $0.5-3.3$ \\
\hline
\end{tabular}


Table 1: Samples investigated for hot $\left(850{ }^{\circ} \mathrm{C}\right)$ fragmentation experiments with average porosity value for any rock variety, the number of experiments performed to quantify the threshold and the threshold value. The total amount of experiments sums up to approx. 400 . For petrologic characterization of the used samples, please see the following references: Unzen [48], Merapi [49], Etna [50], Campi Flegrei [51, 52], Santorini [53], Montserrat [54], Mt. St. Helens [55]. 


\begin{tabular}{|l|l|l|l|}
\hline & $\begin{array}{l}\text { “Tensile strength” at } \\
\text { best fit (MPa) }\end{array}$ & Fit Standard Error & Adj. R $^{2}$ \\
\hline Alidibirov & 5.875 & 2,899 & 0.847 \\
\hline This Paper & 0.995 & 3,646 & 0.758 \\
\hline McBirney \& Murase & 1.031 & 4,110 & 0.757 \\
\hline Zhang & 9.442 & 4,574 & 0.620 \\
\hline
\end{tabular}

Tab 2: Fit quality for the best-fit-plots for the three theoretical models and our relationship to the experimental data. Keep in mind, that the model of McBirney and Murase can not be applied to porosity values above $60 \%$. The achieved fit quality is therefore not fully comparable to the other two models. (The Fit Standard Error is defined as the square root of the sum of the squared errors divided by the degree of freedom.) 